\title{
O fator humano na gestão de RH
}

\author{
Fernando Antônio da Silva é administrador de empresas e \\ conferencista do curso de Direção Estratégica de Recursos \\ Humanos do GVpec - Programa de Educação Continuada - da \\ EAESP/FGV. Em 1996, publicou o livro Administrando pessoas: \\ reflexões do cotidiano de um executivo de recursos humanos, no qual \\ relata sua formação e vivência na área de RH. Em entrevista \\ concedida à RAE Light, Fernando Antônio analisa a gestão de \\ Recursos Humanos no Brasil e a importância do Ser Humano nos \\ planos estratégicos das organizaçōes.
}

\author{
por Renato Guimarães Ferreira
}

$\boldsymbol{R A E}$ Light: A tentativa de uma maior inserção do Brasil em uma economia globalizada coloca diante das empresas aqui instaladas uma série de desafios em termos de competitividade. Qual é, em sua opinião, a contribuição que a gestão de Recursos Humanos pode dar para a superação desses desafios?

Fernando Antônio: A competitividade pressupõe uma mão-de-obra altamente qualificada e apta a absorver novas tecnologias. Os novos tempos exigem comprometimento e motivação elevada.

É dentro deste contexto que uma gestão de recursos humanos atualizada deve aportar uma contribuição significativa, para que a empresa alcance seus objetivos maiores, dentro do conceito de crescimento e perenidade dos negócios, lembrando que resultados são obtidos através de pessoas.
$\boldsymbol{R A} \boldsymbol{E}$ Light: Uma das dimensões fundamentais do desafio da competitividade é a busca contínua por maior produtividade. Isso tem provocado, entre outras coisas, um enxugamento das estruturas organizacionais e uma experimentação de novos modelos de gestão, que exercem uma pressão crescente sobre o desempenho das pessoas. Você acredita que é possível compatibilizar qualidade de vida com essa demanda por maior produtividade?

Fernando Antônio: Novos modelos de gestão, ao meu ver, precisam privilegiar o Ser Humano para se tornarem viáveis. Assim, a preocupação com a qualidade de vida passa a ser não apenas do colaborador mas também da organização, pois pessoas satisfeitas e motivadas produzem mais e melhor. Já existem casos concretos de empresas que alcançaram êxito e conseguiram compatibilizar qualidade de vida com produtividade. Quanto à realidade brasileira, é ver para crer.

$\boldsymbol{R A} \boldsymbol{E}$ Light: O processo de globalização é um processo que transforma de maneira radical a estrutura de oportunidades existentes no mercado de trabalho. Ele penaliza sobretudo aqueles que já se encontram na periferia do sistema, como por exemplo, os trabalhadores com baixa qualificação. Diante desse fato, o que é que as organizações socialmente responsáveis e atuantes em mercados competitivos podem fazer?

Fernando Antônio: Acredito que a sociedade civil organizada pode contribuir de maneira efetiva na qualificação dos "excluídos" do processo. Empresas, sindicatos de classe, Rotary Club, Sebrae, 
Sistema SENAI/SESC, entidades de ensino, órgãos governamentais e cidadãos, comprometidos com a sobrevivência das camadas da sociedade menos privilegiadas, deveriam juntar esforços e montar programas de atualização profissional nos diversos níveis - operacional, supervisão e gerência; de preparação de administradores de pequenos negócios e operacionalizar empréstimos para viabilizar os projetos. Tenho absoluta certeza de que não apenas os menos afortunados mas a sociedade como um todo se beneficiariam com ações dessa natureza.

RAE Light: Algumas organizações têm utilizado metodologias alternativas, e de certa forma polêmicas, como a grafologia, a numerologia e até mesmo a astrologia para a identificação de perfis em processos de seleção. Qual é sua opinião a esse respeito e que cuidados você recomendaria àqueles que pretendem utilizá-las? Seria particularmente interessante ler suas recomendações a respeito da postura de um profissional de Recursos Humanos que se vê diante da necessidade de comunicar a um candidato cético sua não aprovação em um processo de seleção baseado em tais metodologias.

Fernando Antônio: Acho que a busca de novas metodologias de seleção é uma postura saudável, sejam elas clássicas ou alternativas. Porém, todas devem ser analisadas com critério e bom senso, sem

\section{O mais importante é entender que a educação é investimento $e$ atrelar 0 programa de treinamentol desenvolvimento/educação ao plano estratégico da organização.}

Fernando Antônio: Tenho observado que, além de uma sólida formação acadêmica, é preciso destacar a atualização permanente e uma rede social ativa, a capacidade de adaptação às mudanças, capacidade de realizar objetivos, habilidade de gerir pessoas e a maturidade emocional, hoje tão em voga, como elementos que diferenciam os profissionais de sucesso dos demais.

modismos ou mesmo preconceitos. Por outro lado, como as metodologias servem para oferecer elementos às decisões e por si não possuem caráter eliminatório, diria que um bomfeed-back para um candi-
$\boldsymbol{R A E}$ Light: Ao longo dos últimos anos, quais as principais modificações que você percebeư no papel do gerente e que direção elas deverão tomar nos próximos anos?
Fernando Antônio: Houve uma acentuada mudança na qualidade da liderança, na exigência de se ter uma visão de conjunto da empresa e do negócio e uma sensibilização para o fator humano. Esta tendência deve continuar, mas acrescentaria que o gerente passará a exercer o papel de grande facilitador de sua equipe de trabalho, assumindo definitivamente seu papel de educador; será um generalista, porém sem perder sua competência de origem; trabalhará por projetos, exercendo cargos por períodos de tempo determinados; será, a partir de seu próprio exemplo, um incentivador do auto-desenvolvimento; será um competente gestor de pessoas; terá uma visão profunda do negócio e do mercado e estará profundamente comprometido com os objetivos da empresa.

RAE Light: A atuação no cenário organizacional contemporâneo tem exigido um processo continuado de capacitação e desenvolvimento, cuja responsabilidade e direção vêm sendo cada vez mais assumidas pelos próprios profissionais. Quais são, em sua opinião, as estratégias mais eficazes de capacitação e desenvolvimento para atuação em um mercado crescentemente competitivo?

Fernando Antônio: Colocar em prática o conceito de educação permanente e, para isso, realizar parceira com universidades competentes, incentivar ações de autodesenvolvimento, investir no desenvolvimento de programa para jovens talentos e desenvolver programas personalizados de educação gerencial, para necessidades específicas. Mas, o mais importante é entender que a educação é investimento e atrelar o programa de treinamento/desenvolvimento/ educação ao plano estratégico da organização. 
$\boldsymbol{R A E}$ Light: É possível encontrar hoje no mercado um conjunto relativamente amplo de alternativas de remuneração, atestando de certa forma a crise do sistema tradicional de remuneração atrelada a cargos. Que tipo de remuneração você acredita que possa promover um grau mais elevado de comprometimento e motivação dos colaboradores de uma dada organização?

Fernando Antônio: Estou crente que combinar um sistema de remuneração por habilidades com um bom programa de remuneração variável, vinculada a resultados, venha responder às necessidades atuais e futuras das empresas. $\mathrm{Pa}$ gar por habilidades, para mim, significa um grande avanço na forma de compensação, pois o torna quase personalizado, portanto mais justo. Quanto ao variável "amarrado" à contribuição do indivíduo é uma tendência que já observamos mesmo no Brasil. Porém, acho que falta mais ousadia para tornálo mais atrativo e motivador. Acredito que a área de compensação apresenta um grande desafio a criatividade dos administradores de pessoas.

$\boldsymbol{R A E}$ Light: As organizações contemporâneas têm contado cada vez mais com a colaboração de temporários e de terceiros para a consecução de seus objetivos. Na perspectiva da gestão do fator humano, o que pode ser feito para que haja um verdadeiro alinhamento de esforços, uma vez que a temporalidade que marca essas relações pode eventualmente ameaçar o comprometimento que se faz necessário para a obtenção contínua de qualidade e produtividade?

Fernando Antônio: Para mim, este é um caminho definitivo. Mas, como foi bem colocado na pergunta, como convergir es- forços de populações com tratamentos tão diferenciados? Primeiramente, é preciso ter o conceito de produtividade alinhado ao serviço prestado por terceiros. Parece-me que ainda privilegiamos o fator custo, em detrimento da produtividade, razão maior de terceirização. Por acaso não dizemos que nosso core competence é fazer tal produto e, portanto, os outros serviços devem ser realizados por especialistas? A verdade é que fazemos esta afirmação, mas na hora da contratação de terceiros, como regra geral, os custos pesam muito mais do que a qualidade e a produtividade dos serviços que estamos contratando. Portanto, a saída é ajustar nossos conceitos aos terceiros, inclusive

quanto ao nosso relacionamento no cotidiano, pois a partir do momento que se sentirem motivados, tenderão a contribuir para os objetivos da organização.

$\boldsymbol{R A E}$ Light: A participação ativa dos colaboradores de uma organização em seu processo de gestão sempre traz melhores resultados? Se sim, como é que isso se dá? Se não, quais são, em sua opinião, os limites da gestão participativa?

Fernando Antônio: Não tenho dúvidas de que o modelo participativo é aquele que produz maiores e perenes resultados. Mas não é panacéia que resolve todos os problemas e há um caminho de aprendizagem que precisa ser cumprido. A dimensão tempo é muito importante neste processo, aliada a metodologia e comprometimento de toda organização. Quanto a limites, como se trata de um processo evolutivo fica muito difícil prevê-los.

RAE Light: A área de Recursos Humanos é vista por muitos profissionais como uma área em que há mais discurso do que ação. Você concorda com essa visão? Se sim, por que isso ocorre dessa forma?

Fernando Antônio: Concordo integralmente. Acredito que durante muito tempo alguns gestores da área esconderamse debaixo do manto do subjetivismo para justificar a não apresentação de resultados mensuráveis. Faltava visão do negócio e, até arriscaria, comprometimento com os objetivos da organização; possuíam uma visão muito mais instrospectiva. Por outro lado, por não entender a importância do fator humano nos resultados terminais, os dirigentes pouco exigiam da área de recursos humanos. Verdade? Um ponto de vista. Mas esta realidade está mudando rapidamente, pois tanto os gestores da área como os dirigentes das organizações começam a entender o significado da contribuição que pode dar uma gestão eficaz de pessoas e a entender que resultados mensuráveis podem e devem ser gerados. Afinal, contra fatos não há argumentos.

Fernando Antônio da Silva é administrador de empresas, Diretor Corporativo de Desenvolvimento Organizacional da Votorantim Cimentos Ltda., Presidente do ILACE - Instituto Latino Americano de Criatividade e Estratégia e autor do livro Administrando pessoas - reflexões do cotidiano de um executivo de $R H$ (Negócio Editora/Biblioteca RAE, 1996).

Renato Guimarães Ferreira é Professor do Departamento de Administração Geral e Recursos Humanos da EAESP/ FGV. 